Article

\title{
An Experimental Investigation of Wake Characteristics and Power Generation Efficiency of a Small Wind Turbine under Different Tip Speed Ratios
}

\author{
Yu-Ting $\mathrm{Wu} * \mathbb{D}$, Chang-Yu Lin and Che-Ming Hsu \\ Department of Engineering Science, National Cheng Kung University, Tainan 701, Taiwan; \\ n98071063@mail.ncku.edu.tw (C.-Y.L.); n96061240@mail.ncku.edu.tw (C.-M.H.) \\ * Correspondence: bulawu@mail.ncku.edu.tw; Tel.: +886-6-2757575 (ext. 63341); Fax: +886-6-2766549
}

Received: 3 February 2020; Accepted: 21 April 2020; Published: 24 April 2020

\begin{abstract}
We carried out a wind tunnel experiment to examine the power generation efficiency of a stand-alone miniature wind turbine and its wake characteristics at different tip speed ratios (TSRs) under the same mean inflow velocity. Resistors in the electrical circuit were adjusted to control the TSRs to $0.9,1.5,3.0,4.1,5.2$, and 5.9. The currents were measured to estimate the turbine power outputs versus the TSRs and then establish the actual power generation coefficient $C_{p}$ distribution. To calculate the mechanical power coefficient, a new estimation method of the mechanical torque constant is proposed. A reverse calibration on the blade rotation speed was performed with given electrical voltages and currents that are used to estimate the mechanical power coefficient $C_{p}$, mech. In the experiment, the maximum $\mathrm{C}_{\mathrm{p} \text {,mech }}$ was approximately 0.358 (corresponding to the maximum $\mathrm{C}_{\mathrm{p}}$ of 0.212 ) at the TSR of 4.1. Significant findings indicate that the turbine at the TSR of 5.2 produces a smaller torque but a larger power output compared with that at the TSR of 3.0. This comparison further displays that the turbine at the TSR of 5.2, even with larger power output, still produces a turbine wake that has smaller velocity deficits and smaller turbulence intensity than that at the TSR of 3.0. This behavior demonstrates the significance of the blade-rotation control (i.e., pitch regulation) system to the turbine operation in a large wind farm for raising the overall farm power productivity.
\end{abstract}

Keywords: Cobra probe; power coefficient; power output; tip speed ratio; wake measurement; wind tunnel experiment

\section{Introduction}

In recent years, green energy has gradually gained attention due to raising awareness of environmental protection. Many clean and pollution-free energy sources (such as wind power, solar power, and hydropower) have been attracting attention and are widely used for electricity production in many countries. In particular, wind power is developing rapidly, and many large wind farms have been built to harvest the energy from the wind in offshore and onshore areas.

In the past years, many previous studies involving single wind turbines have been completed through various research methods such as field measurements [1,2], wind tunnel experiments [3,4], and numerical simulations $[5,6]$. Some studies focused on investigating changes in the wake characteristics of wind turbines exposed to different incoming mean velocities $[7,8]$ and different inflow turbulence intensity levels resulting from surface roughness change [6,9] and thermal stability [10,11]. Significant findings include that the incoming flow with intense turbulence levels, whether induced by surface roughness or thermal buoyancy, can effectively facilitate the wake recovery rate that is along with the generation of large turbulence intensity and strong momentum flux. Turbine rotors operating at the same tip speed ratio (TSR) $\lambda$ but different incoming mean velocities [8] produce wakes that have 
consistent features in terms of normalized wake deficits and turbulence enhancement. The blades of a turbine under different freestream inflow velocities [7] induce the generation of a tip vortex system where the vortex completely breaks down immediately downstream of the rotor operating at a higher TSR (about 12) or collapses further downstream of the turbine with a certain distance up to 10 rotor diameters at a lower TSR (about 7) condition. The above two studies indicate that changing the TSR can lead to significant effects on the characteristics of turbine wakes.

In recent decades, wind tunnel experiments have been widely applied to study the structure and characteristics of small wind turbine wakes using velocimetry, including Cobra probes, Hot-wire probes, and Particle image velocimetry (PIV). Wind tunnel experiments carried out by Iungo [12], Mallipudi et al. [13], Chawla et al. [14], Wang et al. [15], and Wu et al. [16] adopted Cobra probes to collect complex unsteady wakes originated from turbines, rotating objects, and airfoils. Iungo [12] conducted wind tunnel tests with the Cobra probe, and found that the axial velocity component is characterized by a significant wake velocity deficit, which gradually recovers to the incoming wind velocity at further downstream locations, and the vortex generated from near the hub is wholly diffused at downstream distances of more than four rotor diameters. Chawla et al. [14] conducted wake measurements of airfoils by employing the Cobra probe to understand the wake characteristics and then facilitate the improvement of the airfoil efficiency through a suction control. Mallipudi et al. [13] used the Cobra probe to examine the wake characteristics of stationary and rotating objects. They conducted an in-situ calibration through the comparison of the manufacturer specifications and then confirmed that the Cobra probe could achieve accuracies of wind speed within $0.5 \mathrm{~m} \mathrm{~s}^{-1}$, wind direction less than 1 degree in yaw and pitch, and a sufficient sampling frequency up to approximately $1500 \mathrm{~Hz}$. Wang et al. [15] used the Cobra probe and PIV to examine unsteady wakes from a single-rotor turbine and a twin-rotor turbine in the wind tunnel experiment. The comparison of the wake measurements in the near wake region at $x / d=2$ showed good agreement (here, $x$ and $d$ denote the streamwise position and the rotor diameter, respectively). Wu et al. [16] compared measurements of stand-alone turbine wakes collected from the Cobra probe and the Hot-wire probe and presented the wakes that have a reasonably consistent structure and characteristics in terms of mean wake velocity and turbulence intensity. Based on the above-mentioned previous studies, the Cobra probe has become a widely-used and reliable velocimeter appropriate for measurements of complex turbine wakes in a wind tunnel.

A real utility-scale wind turbine has a pitch regulation system to control the blade rotating speed. Generally, a turbine pitch regulation system keeps the blade rotating speed as a constant as inflow velocity is greater than $10 \mathrm{~m} \mathrm{~s}^{-1}$ (e.g., Vestas V80). Hence, a turbine TSR decreases as the inflow wind speed increases, although the blade rotating speed does not change. Studies involving the estimation of the turbine power coefficient have also been extensively conducted in wind tunnel experiments [4,17-19] and field measurements [20]. Their results consistently show that the power coefficient as a function of the TSR has a parabolic distribution with a maximum of about $0.3-0.45$ between TSR $=4$ and TSR $=8$. Some studies present that the shaft torque as a function of the blade angular velocity has a similar parabolic distribution with the maximum at a blade angular velocity. These results indicate that the initial increase of the blade rotation speed can raise the blade generating shaft torque and the power generation efficiency, but too high blade rotation speeds lead to a reduction in the torque and power generation efficiency. This behavior illustrates open issues related to turbine pitch regulation strategy, in particular the optimal strategy to target the maximum power coefficient, the maximum shaft torque, or a higher blade angular velocity with a moderate shaft torque. A series of wake measurements under different TSR conditions is still lacking, and the relationship with the power generation efficiency is not well understood. A previous study by Dilip and Porte-Agel [21] showed that pitch regulation, which is applied to adjust the blade angular velocity of the upstream turbines with a decreased pitch angle of -2 degrees (i.e., changes the original TSR of the rotor) in the in-line two-turbine simulations, can mitigate the wake effects on the downstream turbines and increases the total power output by $2.8 \%$ at a lower inflow turbulence condition. Such a strategy can be viewed as an alternative to increasing the power produced in a massive wind farm operation in the future. 
Some of the studies mentioned above [8-12] have conducted wind tunnel experiments focusing on the stand-alone wind turbine wake characteristics under the influence of surface roughness change, surface temperature variation, and different incoming wind velocities. However, these studies did not further systemically investigate the relationship between the power generation efficiency and the wake characteristics. A detailed investigation of the wake characteristics of the single turbine and its power generation efficiency at the different TSR conditions is still lacking. Therefore, this study conducted a wind tunnel experiment to examine power generation efficiency and wake characteristics of a stand-alone turbine operating at different blade angular velocities under the same incoming mean wind velocity. Section 2 details the set-up of the wind tunnel experiment, the information on the miniature wind turbine model, and the specification of the selected measuring instruments. Section 3 discusses the results and methods used to estimate the torques, the power output, and the power coefficient. Vital turbulence statistics, including the mean streamwise and vertical velocities, the turbulence intensity, and the momentum flux, as well as a comparison of results under the different blade angular velocities, are presented and discussed in Section 4. A summary is given in Section 5.

\section{Experimental Setup}

The experiment was conducted in an in-house open-type wind tunnel (shown in Figure 1) located in the basement at the Department of Engineering Science, National Cheng Kung University, Tainan, Taiwan. The test section size of this tunnel is $4.4 \mathrm{~m}$ in length, $0.8 \mathrm{~m}$ in width, and $0.8 \mathrm{~m}$ in height. The wind-making facility includes an SFBM-36D fan made by the Shuenn Farn Ventilator Industrial Co. and a VFD-S frequency converter from Delta. The fan is placed downstream of the tunnel to suck the airflow passing through the test section. The VFD-S frequency converter is used to control the fan rotation speed with a prescribed frequency of $10-60 \mathrm{~Hz}$, so that the incoming flow velocity inside the test section can be adjusted from 1 to $10 \mathrm{~m} \mathrm{~s}^{-1}$.

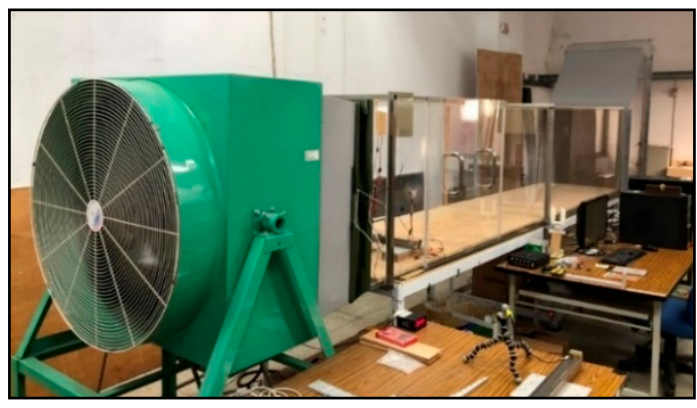

(a)

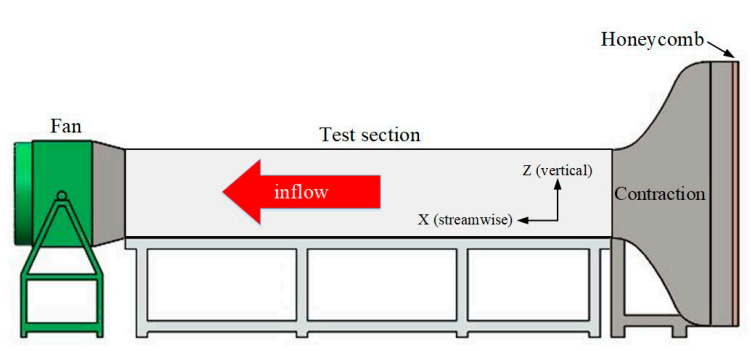

(b)

Figure 1. (a) Picture of the wind tunnel; and (b) schematics of the wind tunnel.

In the experiments, the air temperature in the basement was controlled at $25{ }^{\circ} \mathrm{C}$ by two air conditioners. A constant frequency of $30 \mathrm{~Hz}$ was set in the VFD-S frequency converter to produce the freestream velocity of about $6.1 \mathrm{~m} \mathrm{~s}^{-1}$ in the test section of the tunnel. We chose the Maxon DCX-12-L motor as the turbine dc generator driven by a $15-\mathrm{cm}$-diameter rotor made by a ProJet 3510 3D printer inside the tunnel. Table 1 lists some Maxon DCX-12-L motor information. The blade airfoil is NACA 0012. The blade chord length and twist angle are optimized using the blade element momentum theory. The blade geometry information is given in Table 2, and the detailed design procedure of the turbine rotor are given in the work of $\mathrm{Wu}$ et al. [16]. 
Table 1. Maxon DCX-12-L motor specification.

\begin{tabular}{cc}
\hline Cases & Value \\
\hline Nominal voltage & $9 \mathrm{~V}$ \\
Nominal current & $0.437 \mathrm{~A}$ \\
Nominal speed & $5750 \mathrm{rpm}$ \\
Torque constant & $9.66 \mathrm{mN} \mathrm{m} \mathrm{A}^{-1}$ \\
\hline
\end{tabular}

Table 2. Radial variation of the twist angle and chord length for the turbine blade.

\begin{tabular}{cccccccccc}
\hline Radius & $(\mathrm{m})$ & 0.01 & 0.02 & 0.03 & 0.04 & 0.05 & 0.06 & 0.07 & 0.075 \\
Twist & $(\mathrm{deg})$ & 42.85 & 24.05 & 14.64 & 9.31 & 6.01 & 3.97 & 2.86 & 3.18 \\
Chord & $(\mathrm{mm})$ & 13.9 & 14.7 & 14.7 & 14.1 & 13.1 & 11.8 & 10.2 & 8.2 \\
\hline
\end{tabular}

In this study, the experimental goal was to systemically investigate the relationship between the turbine power generation efficiency and the wake characteristics at different TSR conditions under the same hub-level incoming velocity of $6.1 \mathrm{~m} \mathrm{~s}^{-1}$. Estimates of the power coefficient at different TSRs were needed for evaluating the turbine power generation efficiency, which required a further examination of the actual power output and the friction-induced power losses. To achieve this goal, the Maxon DCX-12-L motor was used as the turbine generator and connected to a resistor and a dc voltmeter in a series circuit. The resistor could be adjusted to achieve the turbine blade rotating at the different angular velocities (i.e., different TSRs) under the same hub-level incoming velocity. The TSRs considered are: $0.9,1.5,3.0,4.1,5.2$, and 5.9. A dc voltmeter was used to measure the total resistance and the current in the circuit at each TSR condition. A Cobra probe was used to measure the three velocity components (streamwise, spanwise, and vertical) at positions across the turbine wakes and the inflow velocity.

Figure 2 shows the measuring chain schematic. Measurements taken in the experiment include the instantaneous flow velocity components (streamwise, spanwise, and vertical), the blade angular velocity, the generator-produced electric current, and the total resistance of the circuit. The three velocity components were measured using a calibration-free, 4-hole Cobra probe manufactured by Turbulent Flow Instrument. The Cobra probe was positioned at the turbine hub level to collect the instantaneous wind speed data laterally from $y=-230$ to $230 \mathrm{~mm}$ (with intervals of $7.5 \mathrm{~mm}$ from $\mathrm{y}=-150$ to $150 \mathrm{~mm}$ and intervals of $10 \mathrm{~mm}$ from $\mathrm{y}=-230$ to $-150 \mathrm{~mm}$ and from $\mathrm{y}=150$ to $230 \mathrm{~mm}$ ) at the streamwise locations of $x / d=1,2,3,4,5,6,7$, and 8 as well as at the inflow (at $x / d=0$ without the model turbine placement), as shown in Figure 2. The measurements for each TSR condition have a total of 513 measurement points, and the measuring time was $120 \mathrm{~s}$, with a sampling rate of $1200 \mathrm{~Hz}$ on each point. The actual measuring period for each case was approximately $24 \mathrm{~h}$. The blade angular velocity was measured using an ACT-3X series panel tachometer equipped with the ROLS24-W remote optical laser sensor from Monarch Instrument. The electric current and the total resistance in the circuit were measured by a digital dc Voltmeter.

Figure 3 shows a picture of the small wind turbine placed in the wind tunnel. The turbine rotor has a diameter of $15 \mathrm{~cm}$ and a hub height of $26 \mathrm{~cm}$. Vertical profiles of the inflow mean velocity and the turbulence intensity (measured at $x / d=0$ and $y / d=0$ without the model turbine placement) are presented in Figure 4. Here, the mean streamwise velocity was set to approximately $6.1 \mathrm{~m} \mathrm{~s}^{-1}$, and the turbulence intensity was around $5 \%$. The turbulence intensity (TI) is defined as follows:

$$
T I=\frac{\sqrt{\sigma_{u}^{2}+\sigma_{v}^{2}+\sigma_{w}^{2} 3}}{\bar{u}_{\mathrm{hub}}}
$$

where $\bar{u}_{\text {hub }}=6.1 \mathrm{~m} \mathrm{~s}^{-1}$ is the incoming mean velocity at the hub height and $\left(\sigma_{u}{ }^{2}, \sigma_{v}{ }^{2}, \sigma_{w}{ }^{2}\right)$ denote the velocity variance components in the streamwise, spanwise, and vertical directions, respectively. In Equation (1), TI can be considered as the "total" turbulence intensity, which is composed of streamwise 
turbulence intensity $\mathrm{I}_{\mathrm{u}}=\sigma_{u}{ }^{2} \bar{u}_{\mathrm{hub}}$, spanwise turbulence intensity $\mathrm{I}_{\mathrm{v}}=\sigma_{v}{ }^{2} \bar{u}_{\mathrm{hub}}$, and vertical turbulence intensity $\mathrm{I}_{\mathrm{W}}=\sigma_{w}{ }^{2} \bar{u}_{\text {hub }}$. The turbulence intensity is an index that can be used to quantify the magnitude of the turbulence properties.

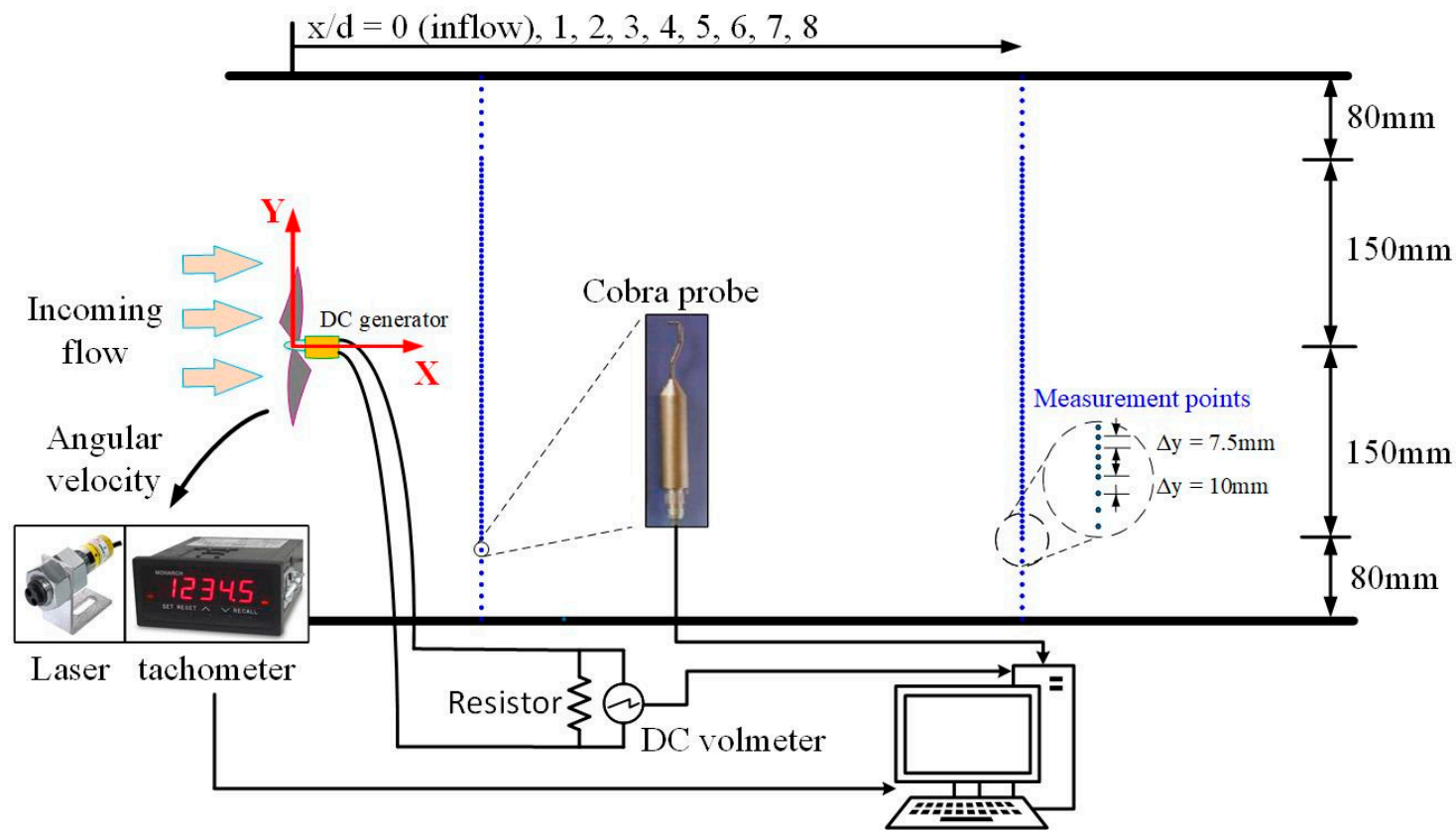

Figure 2. Schematics of the instrument deployment and the measurement locations on the horizontal plane at the hub level.
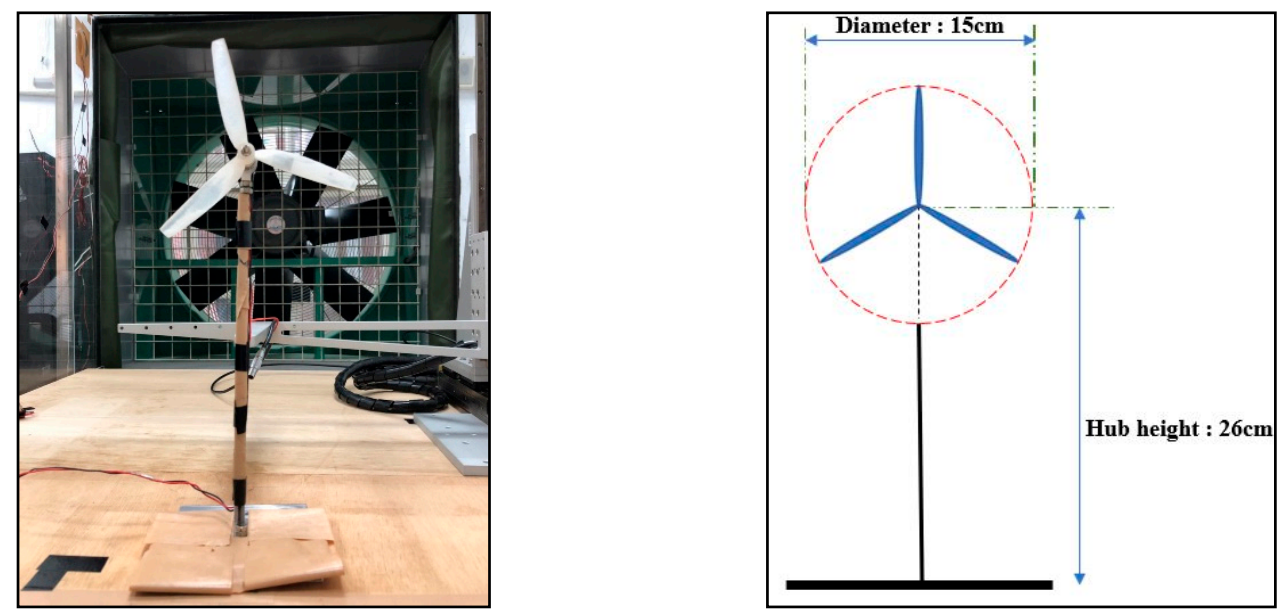

Figure 3. Picture and schematic geometry of the miniature wind turbine. 


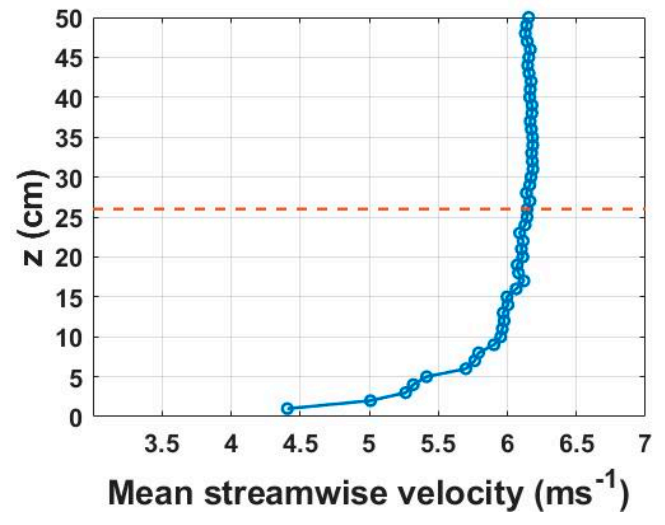

(a)

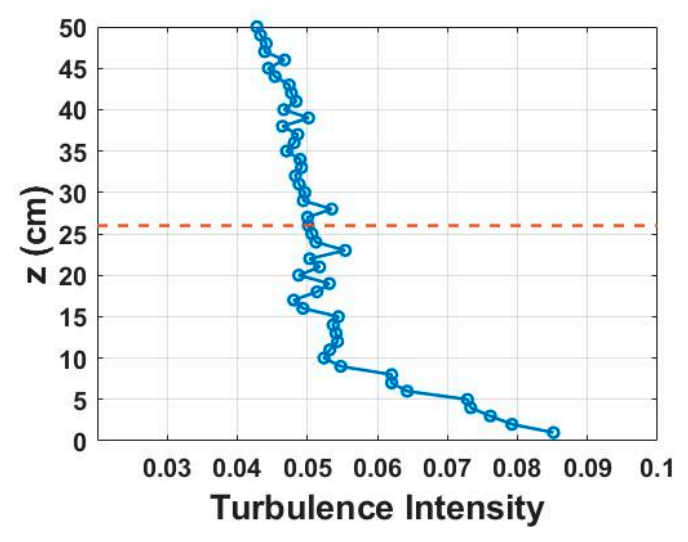

(b)

Figure 4. Vertical profiles of the incoming flow condition: (a) mean streamwise velocity; and (b) total turbulence intensity. The orange dashed lines represent the turbine hub level.

During the experimental measurements, the generator was connected to a resistor and a dc Voltmeter in a series circuit, where the adjustment of the resistor could control the blade angular velocity by changing the load of the circuit (i.e., altering the total resistance of the circuit) under the same incoming speed. Here, we selected six different resistors to bring about total resistances $R_{t}$ of 9.5, 10.5, 10.9, 14.4, 31.2, and $88.8 \mathrm{ohms}$ (given in Table 3) in the circuit, which led to the blade angular velocities $\Omega$ of approximately $675,1134,2358,3199,4060$, and $4558 \mathrm{rpm}$, respectively. These blade angular velocities corresponded to the different TSRs of $0.9,1.5,3.0,4.1,5.2$, and 5.9. In the experiments, the Reynolds number (based on the incoming mean velocity at the hub height $\bar{u}_{\text {hub }}$ and the turbine rotor diameter $d$ ) was $\operatorname{Re}_{\mathrm{d}}=\bar{u}_{\mathrm{hub}} d / v=6.1 \times 10^{4}$. The chord-based Reynolds number, $\operatorname{Re}_{\text {chord }}=\bar{u}_{\text {hub }} \bar{c} / v$ (based on the average chord $\bar{c}$ about $0.01 \mathrm{~m}$ and the blade tip speed $\bar{u}_{\text {tip }}$ ), varied from $5.4 \times 10^{4}$ at a TSR of 0.9 to $2.4 \times 10^{4}$ at a TSR of 5.9. Moreover, statistics of wake measurements and estimations of power coefficients with and without the consideration of the friction-induced losses are the main focus of this study and presented next.

Table 3. Measurements and estimations for the turbine operations under different TSRs.

\begin{tabular}{ccccccccccc}
\hline Case & $\begin{array}{c}\boldsymbol{R}_{\boldsymbol{t}} \\
(\mathbf{o h m})\end{array}$ & $\begin{array}{c}\boldsymbol{\Omega} \\
(\mathbf{R P M})\end{array}$ & $\mathbf{T S R}$ & $\begin{array}{c}\boldsymbol{I} \\
(\mathbf{A})\end{array}$ & $\begin{array}{c}\boldsymbol{V} \\
(\mathbf{V o l t})\end{array}$ & $\begin{array}{c}\boldsymbol{P}_{\boldsymbol{o}} \\
(\mathbf{m W})\end{array}$ & $\boldsymbol{C}_{\boldsymbol{p}}$ & $\begin{array}{c}\boldsymbol{Q}_{m} \\
(\mathbf{m N ~ m})\end{array}$ & $\begin{array}{c}\boldsymbol{P}_{\boldsymbol{m}} \\
(\mathbf{m W})\end{array}$ & $\boldsymbol{C}_{\mathbf{p}, \mathbf{m e c h}}$ \\
\hline $\mathrm{C} 1$ & 9.5 & 675 & 0.9 & 0.059 & 0.6 & 33.1 & 0.014 & 0.85 & 59.93 & 0.025 \\
$\mathrm{C} 2$ & 10.5 & 1134 & 1.5 & 0.091 & 1.0 & 87.0 & 0.036 & 1.26 & 149.56 & 0.062 \\
$\mathrm{C} 3$ & 10.9 & 2358 & 3 & 0.177 & 1.9 & 341.5 & 0.142 & 2.41 & 595.48 & 0.248 \\
$\mathrm{C} 4$ & 14.4 & 3199 & 4.1 & 0.188 & 2.7 & 509.0 & 0.212 & 2.56 & 858.84 & 0.358 \\
$\mathrm{C} 5$ & 31.2 & 4060 & 5.2 & 0.116 & 3.6 & 419.8 & 0.175 & 1.59 & 674.94 & 0.281 \\
$\mathrm{C} 6$ & 88.8 & 4558 & 5.9 & 0.047 & 4.2 & 196.2 & 0.082 & 0.70 & 332.11 & 0.139 \\
\hline
\end{tabular}

\section{Power Output Estimation}

In the wind turbine operation, the mechanical power $P_{m}$ is a sum of the power output $P_{o}$ and the friction-induced power loss $P_{f}$. There are three methods to calculate the mechanical power $P_{m}$. One is obtained from the product of the shaft torque $Q_{m}$ and the blade angular velocity $\Omega$ based on the blade element momentum theory. Another is computed from the product of the torque constant $T_{m}$, the electrical current $I$, and the blade angular velocity $\Omega$. The third is from the product of the inertia of the moment $I_{M}$, the blade angular acceleration $\alpha$, and the blade angular velocity $\Omega$ [22-24]:

$$
P_{m}=P_{o}+P_{f}=Q_{m} \Omega=T_{m} I \Omega=I_{M} \alpha \Omega .
$$


It should be pointed out that in Equation (2) the friction-induced power loss exists in the mechanical torque as the airflow drives the blade rotation. This loss has resulted from the friction of the generator shaft $L_{g e n}$ and the friction of the blade surface $L_{\text {blade }}$, which leads to mechanical torque as follows:

$$
Q_{m}=T_{m} I=I_{M} \alpha=Q_{o}+L_{g e n}+L_{\text {blade }}
$$

where $Q_{o}$ is the electromagnetic torque. Application of $Q_{m}=T_{m} I$ to $Q_{o}, L_{g e n}$, and $L_{\text {blade }}$ leads to

$$
Q_{0}=T_{0} I,
$$

where $T_{o}$ is the electromagnetic torque constant,

$$
L_{g e n}=T_{g e n} I
$$

where $T_{\text {gen }}$ is the friction-induced torque loss from the generator shaft,

$$
L_{\text {blade }}=T_{\text {blade }} I
$$

where $T_{\text {blade }}$ is the friction-induced torque loss from the blade surface. The actual power output of a wind turbine can be estimated from the product of voltage $V$ and current $I$ in the circuit, which leads to the two following equations to compute the electromagnetic torque $Q_{o}$ and the electromagnetic torque constant $T_{0}$ by

$$
\begin{gathered}
Q_{o}=V I / \Omega=I^{2} R_{t} / \Omega, \\
T_{o}=V / \Omega=\mathrm{IR}_{t} / \Omega .
\end{gathered}
$$

In Equations (7) and (8), the electrical current, the total resistance, and the blade angular velocity were measured in the experiment. A linear regression of $Q_{0}$ and $I$ can obtain the equation $Q_{o}=7.830 I+0.032$ with a determination coefficient of 0.996 . Note that the $Q_{o}$ unit is a millinewton meter (i.e., $\mathrm{mN} \cdot \mathrm{m})$. Besides, the power coefficient $\left(\mathrm{C}_{\mathrm{P}}\right)$ of a wind turbine is a common index to quantify the performance of power output at an operating condition and is defined as

$$
C_{P}=\frac{2 P_{o}}{\rho \bar{u}_{\text {hub }}^{3} A}
$$

where $\rho$ is the density of the air, and $A$ is the rotor-swept area. The estimated power coefficients of the turbine at the different TSRs are given in Table 3.

Estimates of the two friction-induced torque losses ( $T_{\text {gen }}$ and $\left.T_{\text {blade }}\right)$ require two separate testing experiments. The first testing experiment was to mount a circular aluminum disk on the generator shaft (see Figure 5a). The selected disk has a weight $m_{\text {disk }}=0.1521 \mathrm{~kg}$ and a radius $r=0.06 \mathrm{~m}$. The inertia of momentum for a circular disk can be calculated by $I_{M}=0.5 m_{\text {disk }} r^{2}=2.7378 \times 10^{-4} \mathrm{~kg} \cdot \mathrm{m}^{2}$. During the experiment, we used a direct current power supply (DCPS) to provide the current to the motor to raise the rotating speed of the disk to above 5000 RPM, and then switched to the generator state to record time series data of the electrical current and the rotation speed. Two resistors with 10 and $20 \mathrm{ohms}$ were individually loaded to the generator. The time series data of the electrical current and the rotation speed for the two resistors are shown in Figure 5b,c. To get rid of spikes in the measured data, continuous electrical current and rotating speed distributions were constructed by a polynomial regression (the polynomial coefficients given in Figure $5 b, c$ ) and then used in the torque constant estimation. The angular deceleration of the disk was estimated from the differential of the rotating speed regression polynomial and shown in Figure 5d. In Equation (5), $L_{\text {gen }}$ can be considered as a function of the disk weight $m_{\text {disk }}$ and given in the following

$$
L_{\text {gen }}=T_{\text {gen }} I=m_{\text {disk }} f_{\text {gen }},
$$


where $f_{g e n}$ is a frictional coefficient. In the generator state, the inertia of momentum from the aluminum disk drove the shaft rotation and induced the shaft friction, resulting in the following equation

$$
Q_{m}=T_{m} I=I_{M} \alpha=T_{o} I+m_{\text {disk }} f_{\text {gen }} .
$$

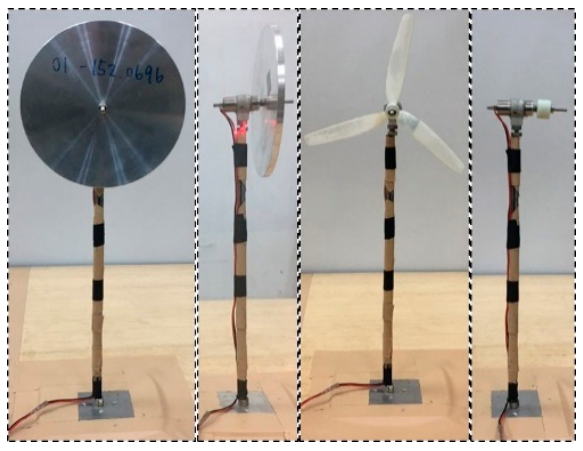

(a)

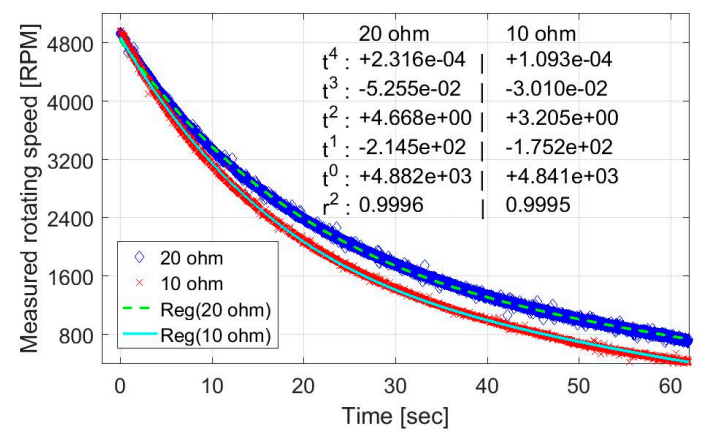

(c)

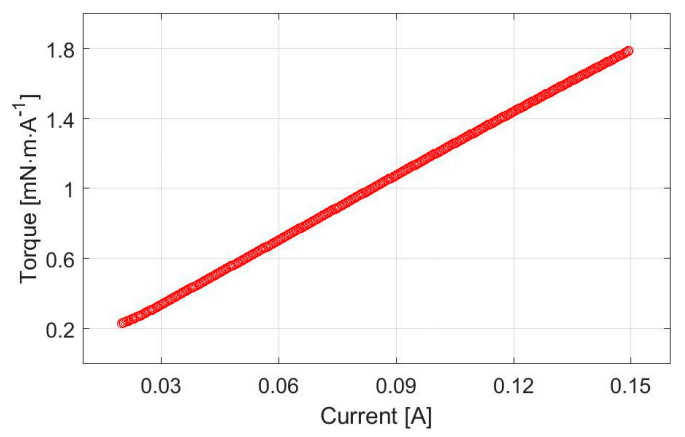

(e)

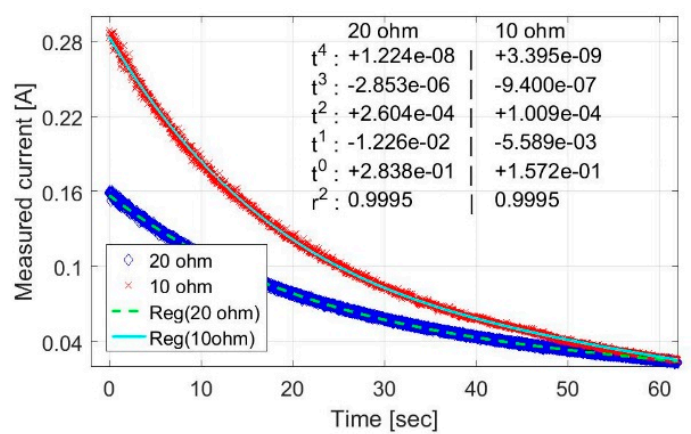

(b)

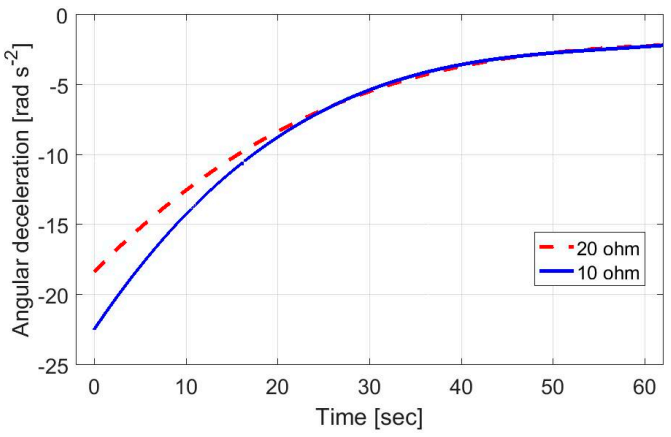

(d)

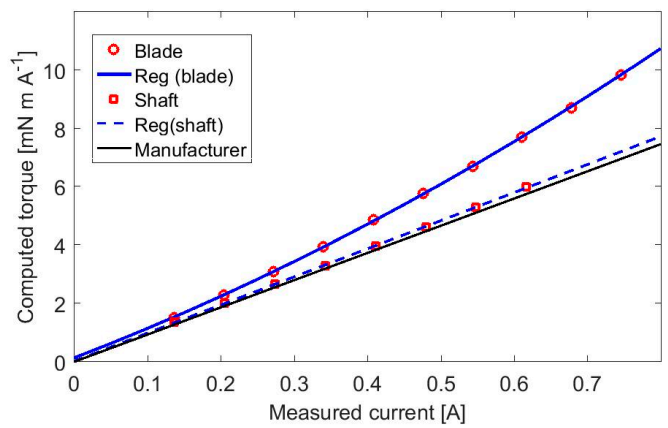

(f)

Figure 5. (a) Photos of the generator mounting with the 12-cm-diameter aluminum disk, the model turbine rotor, and the rotor shaft (without blades); (b) measured electrical currents and the regressed current distributions; (c) measured disk rotating speeds and the regressed angular speed distributions; (d) calculated angular deceleration distributions; (e) distribution of the torque with respect to the current; and (f) distribution of the mechanical torque with respect to current in the motor state.

To calculate $T_{o}$ and $f_{\text {gen }}$, a rotating speed $\Omega$ is selected to find the time $t_{1}$ for 10 ohms and $t_{2}$ for $20 \mathrm{ohms}$ in Figure $5 \mathrm{c}$. In Figure $5 \mathrm{~b}$,d, we can find $I_{1}$ and $\alpha_{1}$ at $t_{1}$ and $I_{2}$ and $\alpha_{2}$ at $t_{2}$, and bring them into Equation (11), resulting in the following equations

$$
\left\{\begin{array}{l}
I_{M} \alpha_{1}=T_{0} I_{1}+m_{\text {disk }} f_{\text {gen }} \\
I_{M} \alpha_{2}=T_{0} I_{2}+m_{\text {disk }} f_{\text {gen }}
\end{array},\right.
$$


Solving Equation (12) can obtain the following

$$
T_{o}=I_{M} \frac{\alpha_{1}-\alpha_{2}}{I_{1}-I_{2}} \text { and } f_{\text {gen }}=\frac{I_{M}}{m_{\text {disk }}} \frac{I_{1} \alpha_{2}-I_{2} \alpha_{1}}{I_{1}-I_{2}} .
$$

The estimation of the torque constant is about $8.487 \mathrm{mN} \cdot \mathrm{m} \cdot \mathrm{A}^{-1}$, which is similar to the computed torque constant value (i.e., 7.830) of the generator with the rotor. The torque-current regressed equation (as shown in Equation (4)) is $Q_{o}=8.487 \mathrm{I}+0.044$. It should be pointed out that this test was done using the aluminum disk with a weight $m_{\text {disk }}=0.1521 \mathrm{~kg}$. For proper application to the model turbine, we have to adopt the rotor mass $m_{\text {rotor }}$ (approximately $20 \mathrm{~g}$ ) to compute the friction-induced torque loss from the generator shaft, resulting in

$$
L_{\text {gen }}=T_{\text {gen }} I=m_{\text {rotor }} f_{\text {gen }}=I_{M} \frac{m_{\text {rotor }}}{m_{\text {disk }}} \frac{I_{1} \alpha_{2}-I_{2} \alpha_{1}}{I_{1}-I_{2}} .
$$

In Figure 5e, the friction-induced torque loss around the shaft is regressed to $L_{g e n}=3.686 I-0.067$. Here, the $L_{g e n}$ unit is a millinewton meter (i.e., $\mathrm{mN} \cdot \mathrm{m}$ ).

In the second testing experiment, a DCPS was used to supply electricity to the motor to examine the torque constants of the motor mounting with the turbine rotor and the rotor shaft separately (shown in Figure 5a). The rotating speed and both given current and voltage from the DCPS were measured to compute the mechanical torque that was later used for regression with the given current to calculate the torque constant (see Figure $5 \mathrm{f}$ ). As given in Table 1, the manufacturer-provided torque constant is $9.66 \mathrm{mN} \cdot \mathrm{m} \cdot \mathrm{A}^{-1}$ at the shaft-no-load condition. For the rotor shaft condition, the regressed equation is $Q_{\text {shaft }}=9.636 I+0.022$, which has a good agreement with the manufacturer-provided torque constant. For the turbine rotor condition, a second-order polynomial was used for a better fit to have the regressed equation $Q_{\text {blade }}=(4.509 I+9.651) I+0.135$. The $L_{\text {blade }}$ could be estimated from the difference of $Q_{\text {blade }}$ and $Q_{\text {shaft }}$, leading to $L_{\text {blade }}=(4.509 I+0.015) I+0.113$. Finally, the $Q_{m}$ calculation could sum up $Q_{o}, L_{g e n}$, and $L_{\text {blade }}$ to acquire the equation $Q_{m}=4.509 I^{2}+12.188 I+0.112$, which was used to calculate the mechanical torque and the mechanical power coefficient (given in Table 3).

In Table 3, the TSR can be converted directly from the blade angular velocity (with a unit RPM) times a factor of $1.288 \times 10^{-3}$ (computed from $2 \pi / 60 \cdot R / \bar{u}_{\text {hub }}=2 \pi / 60 \cdot 0.075 / 6.1$ ). Hence, the angular velocities of 1000, 2000,3000, and 4000 RPM correspond to the TSRs of approximately 1.3, 2.6, 3.9, and 5.2 , respectively. Figure 6 has four subplots containing the relationships of the measured electrical current, the measured total resistance, the estimated generator voltage, the computed power output, the calculated torque, the estimated torque constant, and the power coefficient with respect to the blade angular velocity. As shown in Figure 6a, the measured current increases and then decreases with the increment of the blade angular velocity. The maximum current of $0.188 \mathrm{~A}$ occurs at the C4 condition (TSR $=4.1$ ), whereas the relatively lower currents (less than $0.06 \mathrm{~A}$ ) appear at both the low and high blade-rotating conditions (i.e., $\mathrm{C} 1$ and $\mathrm{C} 6$ ). Besides, the measured currents are found to increase with total resistance at the conditions of TSR $\leq 4.1$ (with $R_{t} \leq 14.4 \mathrm{ohms}$ ). At the conditions of $\mathrm{TSR}=5.2$ and 5.9, the measured currents have an obvious decrease due to the overload with the total resistance of 31.2 and $88.8 \mathrm{ohms}$ in the electrical circuit. This result indicates that the selected turbine generator is suitable for a load of approximately $15 \mathrm{ohms}$ or less in the circuit to achieve the maximum allowable power output. The presence of the overload to the generator breaks down the quasi-steady approximation of electromagnetism to cause the emission of electromagnetic radiation, which leads to the magnet of the generator to lose energy. 


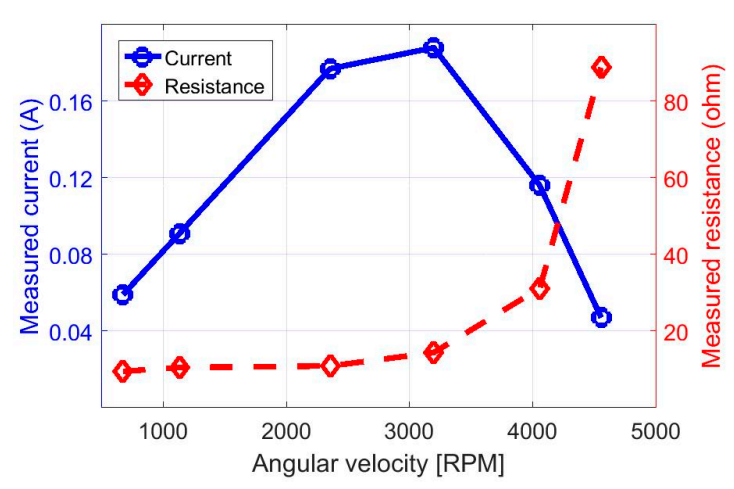

(a)

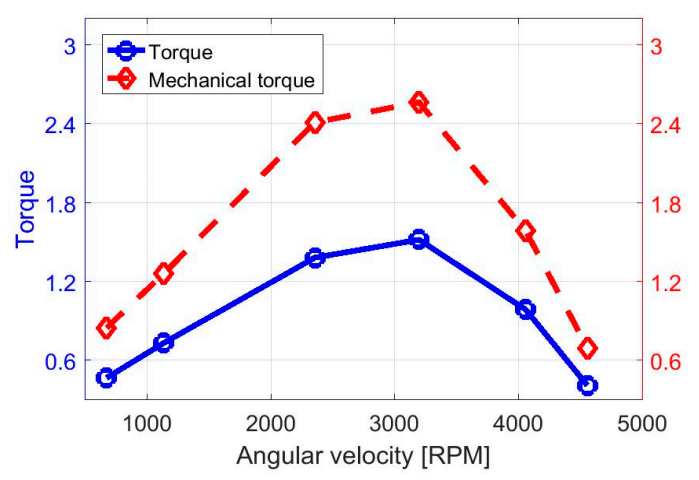

(c)

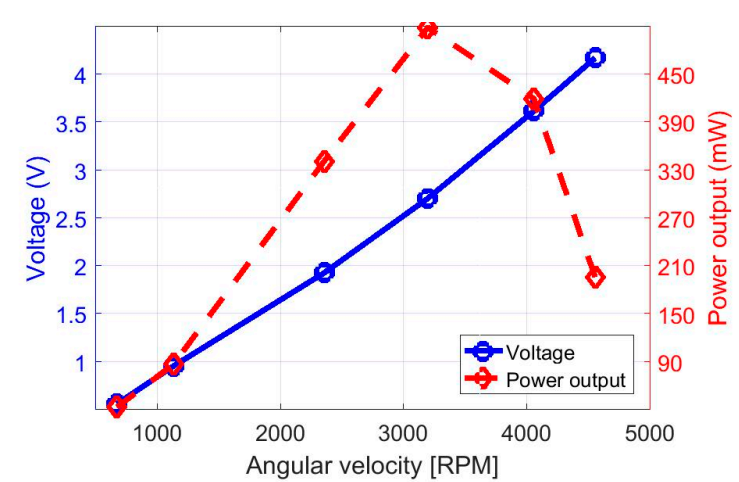

(b)

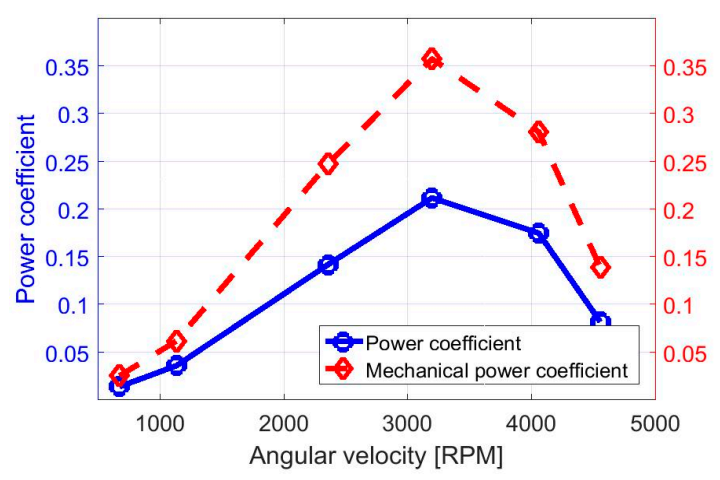

(d)

Figure 6. Distributions of the turbine operating data with respect to blade angular velocity: (a) measured electrical current and total resistance; (b) generator voltage and power output; (c) torque; and (d) power coefficient.

Figure $6 \mathrm{~b}$ shows the distributions of the computed voltage and power output of the generator. The voltage is obtained from the product of the measured current and total resistance and is found proportional to the blade angular velocity with a regression function of $\mathrm{V}(\Omega)=(9.202 \Omega-1272) \times$ $10^{-4}$ and a coefficient of determination 0.996 . The voltage trend demonstrates that the increased blade rotating speed can effectively increase the voltage difference by the generator, which is completely different from the distributions of the measured current and the power output. The power output (shown in Figure 6b) is obtained from the product of the measured current and the voltage and has a maximum of 509 milli-Watt $(\mathrm{mW})$ at the $\mathrm{C} 4$ condition with the TSR of 4.1. Moreover, the TSR increments between $C 3$ and $C 4$ as well as between $C 4$ and $C 5$ are almost the same. The data comparison between $\mathrm{C} 3$ and $\mathrm{C} 5$ shows that the $\mathrm{C} 3$ condition has a larger current generation in the circuit, whereas the $\mathrm{C} 5$ condition has a greater voltage difference from the generator (due to its higher blade angular velocity). The power output at C5 (TSR $=5.2$ ) is relatively larger than that at the TSR of 3.0. This result indicates that the generator can produce more electrical power in the case of a higher blade rotating speed, with a production of a larger voltage and a smaller current in the electrical circuit.

Figure $6 \mathrm{c}$ shows the distributions of the estimated electromagnetic torque and mechanical torque. From the two torque distributions together with the power outputs, $\mathrm{C} 5$ produces less torque but more power output than $\mathrm{C} 3$. This result illustrates the need for blade rotation speed control in maximizing the power output and also demonstrates that a larger torque may not achieve greater energy production. Besides, the estimation of the mechanical torque constant for the Maxon DCX-12-L motor with the rotor is $14.3 \mathrm{mN} \mathrm{m} \mathrm{A}^{-1}$. This torque constant implies electrical-to-mechanical conversion energy as well as losses of electrical connection and frictions on the blade surface, bearing, and so on. Compared to the method proposed by Bastankhah and Porte-Agel [23], this estimation method is relatively simple 
and more straightforward to examine the mechanical torque constant. The power coefficient $C_{p}$ and the mechanical power coefficient $C_{p \text {,mech }}$ of the model wind turbine at the different TSRs are shown in Figure $6 \mathrm{~d}$. The turbine generator driven by the $15-\mathrm{cm}$-diameter rotor has a maximum (i.e., $C_{p}=0.212$ and $C_{p \text {,mech }}=0.358$ ) at the $C 4$ condition with TSR $=4.1$. Both the maximum $C_{p}$ and $C_{p}$,mech based on the measured power and estimated torque, respectively, are very close to the largest power coefficient values of the DCX-14-L motor reported in [23]. This result shows that the proposed method is feasible to estimate the reliable power coefficient. The optimal power coefficients are quite close when the similar generators have been used.

\section{Characteristics of Turbine Wakes}

Measurements of three instantaneous flow velocity components (i.e., $u, v$, and $w$ ) were done with the Cobra probe in the downstream wake region of the turbine and its upstream inflow. Results of mean velocity, turbulence intensity, and momentum flux were analyzed based on statistical methods [25] and are presented next.

Figure 7 shows the contours of the time-averaged streamwise velocity in the hub-level horizontal plane for the turbine operating at the different TSR conditions. To further compare the wake-induced velocity deficits at the different TSRs, Figure 8 shows the comparisons of the lateral profiles of the time-averaged streamwise velocity at the streamwise locations of $x / d=1,3$, and 5 , as well as of the streamwise profiles of the mean velocity $\langle\bar{u}\rangle$. Here, the angle bracket \langle\rangle represents a laterally spatial averaging from $y / d=-0.5$ to 0.5 . From the two figures, both the spatial distribution of the turbine wakes and the magnitude of the wake velocity deficits have changed significantly in different TSR conditions. Coincidentally with the maximum power coefficient $C_{p}=0.212$ at the $C 4$ condition, the turbine rotor operating at the TSR $=4.1$ leads to the strongest turbine wake in terms of the spatial size of the wake (see Figure 7) and its velocity reduction extent (see Figure 8d). This result explains that, at this operation stage, the small turbine extracts the most fluid kinetic energy to achieve the maximum energy output and conversion efficiency and, therefore, produce the strongest turbine wake.

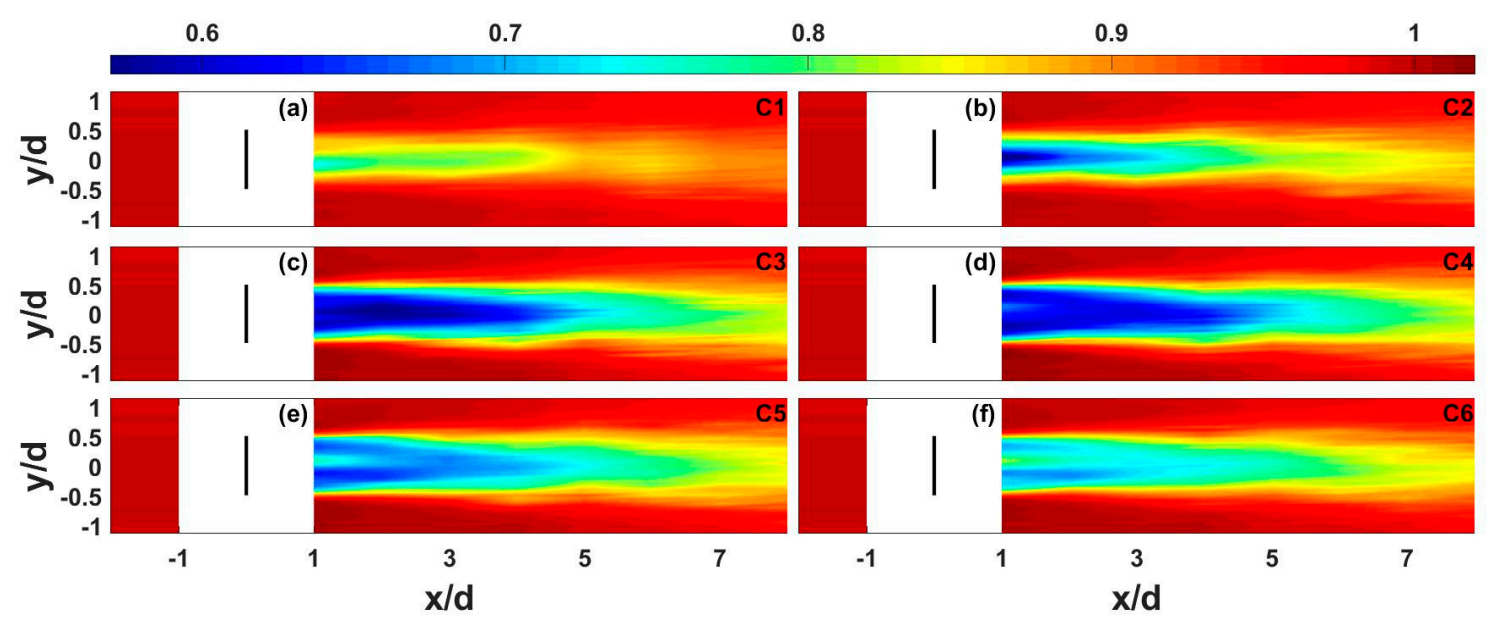

Figure 7. Contour plots of the time-averaged dimensionless streamwise velocity $\bar{u} / \bar{u}_{\text {hub }}$ on a horizontal plane through the turbine hub level under different TSRs of: (a) 0.9; (b) 1.5; (c) 3.0; (d) 4.1; (e) 5.2; and (f) 5.9, corresponding to C1-C6 conditions, respectively. 


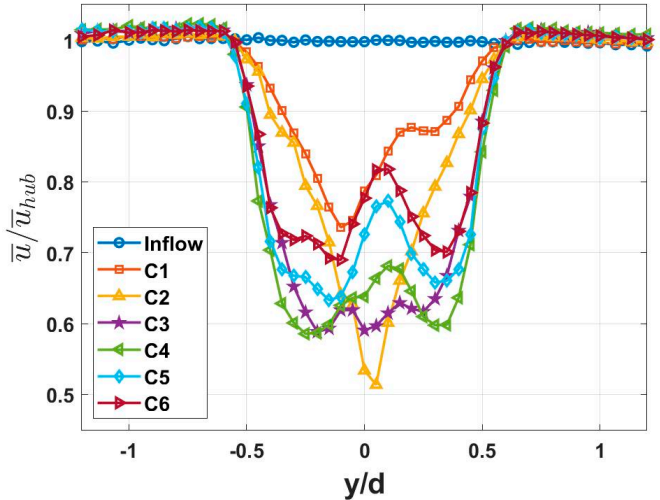

(a)

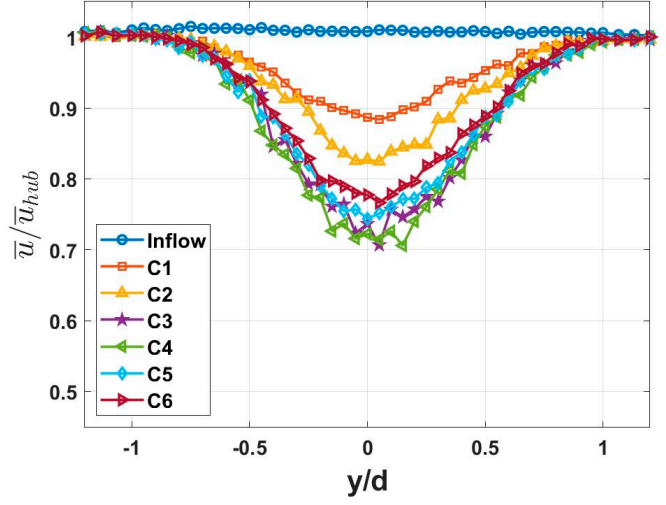

(c)

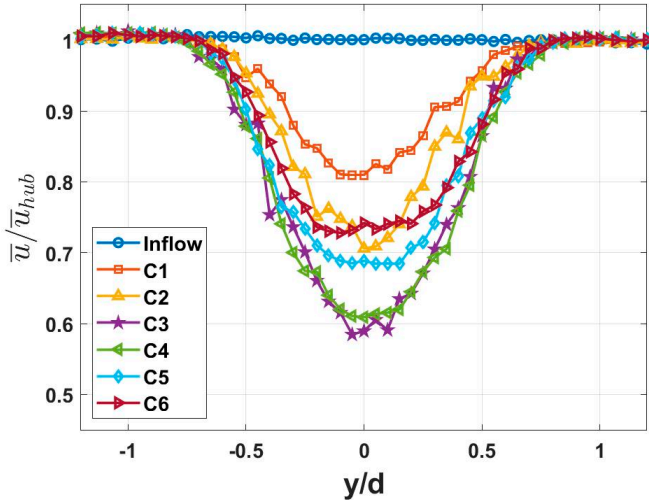

(b)

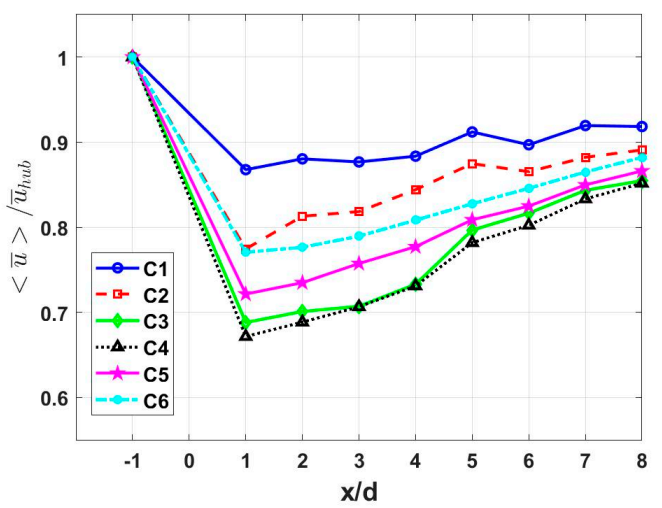

(d)

Figure 8. Lateral profiles of the time-averaged dimensionless streamwise velocity under the $\mathrm{C} 1-\mathrm{C} 6$ TSRs at the streamwise locations: $x / d=1(a) ; x / d=13(b)$; and $x / d=15(\mathbf{c})$; and the distribution of the laterally-averaged streamwise velocity $\langle\bar{u}\rangle(\mathbf{d})$. Here, the angle bracket represents a laterally spatial averaging from $\mathrm{y} / \mathrm{d}=-0.5$ to 0.5 .

In the further discussion associated with the wake velocity distributions affected by the blade under the different TSR conditions, one can divide three equal parts along the radius and then split the rotor-swept area into three regions (i.e., inner circle, middle annulus, and outer annulus), as illustrated in Figure 9. The changes in the wake velocity distributions (particularly in the three regions) under the different TSR conditions at the same streamwise location attracts considerable attention, especially the variability of the wake velocity distributions at $\mathrm{x} / \mathrm{d}=1$ (Figure $8 \mathrm{a}$ ). The turbines, operating at the $\mathrm{C} 1$ and $\mathrm{C} 2$ conditions, lead to the large velocity deficits in the inner region and small velocity deficits in the middle and outer areas (i.e., peripheral area). In particular, the turbine at the $\mathrm{C} 2$ condition produces a V-shaped wake velocity distribution, accompanying the local most significant velocity deficit in the wake center at $\mathrm{x} / \mathrm{d}=1$. At the $\mathrm{C} 5$ and $\mathrm{C} 6$ conditions, the turbine produces large velocity deficits in the peripheral regions and small ones in the inner region, which is similar to an M-shaped distribution. Moreover, the turbine operating at the $\mathrm{C} 3$ and $\mathrm{C} 4$ conditions leads to the large velocity deficits among the three regions (i.e., inner, middle, and outer), with the occurrence of larger electromagnetic torque (as shown in Figure 6c). In the six conditions, one can conclude that the large velocity deficits are associated with more incoming flow kinetic energy converted by the blades into mechanical energy to help drive the blade rotation and the generator shaft, and vice versa. This behavior, together with the mean velocity distributions (shown in Figure 8d), can establish a significant relationship that a large torque will result in the generation of a strong turbine wake downstream. Hence, based on the results in Figures 6-9, the turbine rotor at the $C 3$ and $C 4$ conditions generates larger torques (shown in 
Figure $6 \mathrm{c}$ ) and then causes the downstream wake losses to be much greater than the other operating conditions. These results indicate how the efficiency of the flow momentum extraction by the rotor changes with the blade angular velocity (as well as with the TSR).

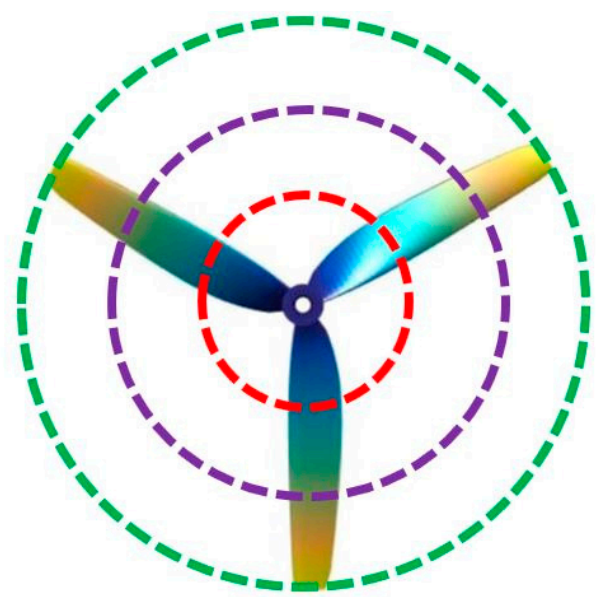

Figure 9. An illustration of a rotor area divided into three regions (inner circle, middle annulus, and outer annulus) along the radial direction.

Figure 10 shows the time-averaged vertical velocity contours in the hub-level horizontal plane for the turbine operating at different TSR conditions. Since the selected turbine rotor rotates clockwise (if one stands the upstream of the turbine) and induces wakes to rotate counter-clockwise, the vertical velocity distribution has the positive upward velocity at $\mathrm{y} / \mathrm{d}<0$ and the negative downward velocity at $y / d>0$. The magnitude of the vertical velocity is found to be larger at the $\mathrm{C} 3$ and $\mathrm{C} 4$ conditions where the rotor has larger torque generation and to be smaller at the $\mathrm{C} 1$ and $\mathrm{C} 6$ conditions, which have lower torque production. Therefore, the torque increment facilitates supplying inputs from the blade reaction force to raise the angular momentum of the wake flow and the vertical velocity magnitude. It should be pointed out that this behavior is different from the extraction of the flow momentum in the streamwise direction that leads to the velocity deficits in the wake.
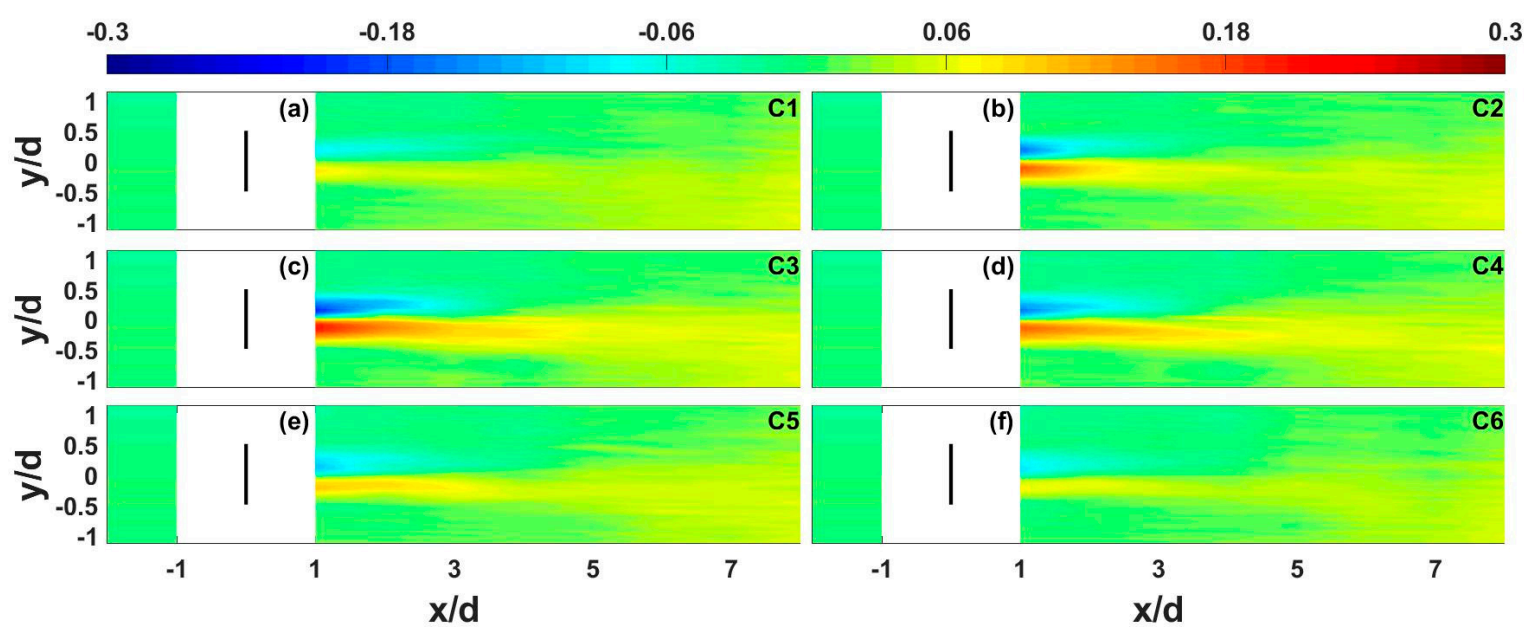

Figure 10. Contour plots of the time-averaged dimensionless vertical velocity $\bar{w} / \bar{u}_{\text {hub }}$ under different TSRs of: (a) 0.9 ; (b) 1.5; (c) 3.0; (d) 4.1; (e) 5.2; and (f) 5.9, corresponding to C1-C6 conditions, respectively.

Figure 11 shows the total TI contours in the hub-level horizontal plane for the turbine operating at the six TSR conditions. To further compare the wake-enhanced TI at the different TSRs, Figure 12 shows the comparisons of the lateral profiles of the total TI at the streamwise locations of $x / d=1,3$, and 
5 , as well as of the streamwise distributions of the mean TI, which is averaged laterally from $y / d=-0.5$ to 0.5 . In the figures, the turbine rotor produces different TI distributions under the considered TSR conditions. The local maximum wake-induced TI is found about 0.18 and appears at $x / d=1$ in the $\mathrm{C} 2$ condition, which is accompanied by the occurrence of the maximum wake deficit (as shown in Figure 8a).

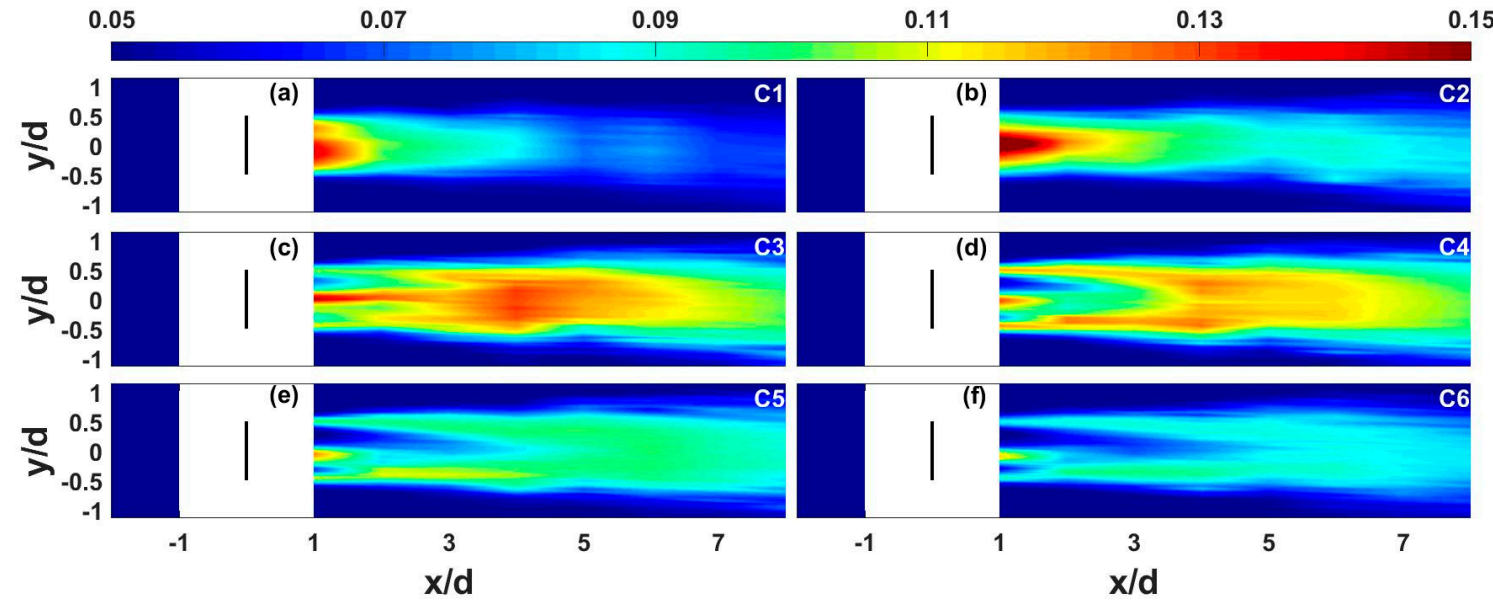

Figure 11. Contour plots of the turbulence intensity under different TSRs of: (a) 0.9 ; (b) 1.5; (c) 3.0; (d) 4.1 ; (e) 5.2; and (f) 5.9, corresponding to C1-C6 conditions, respectively.

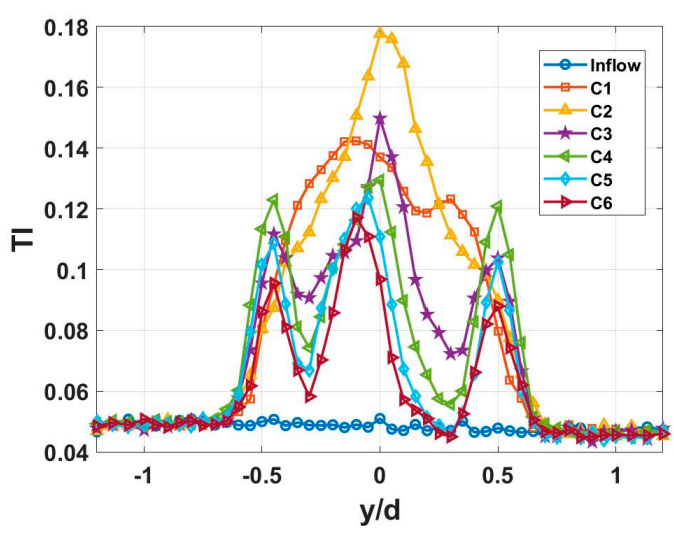

(a)

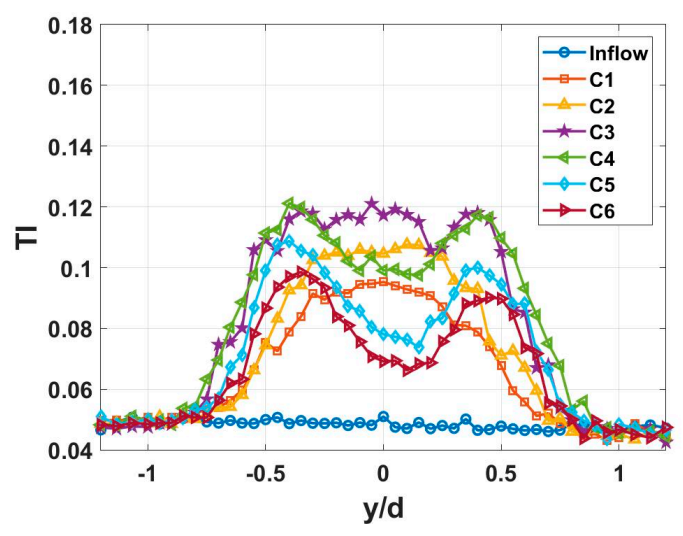

(b)

Figure 12. Cont. 


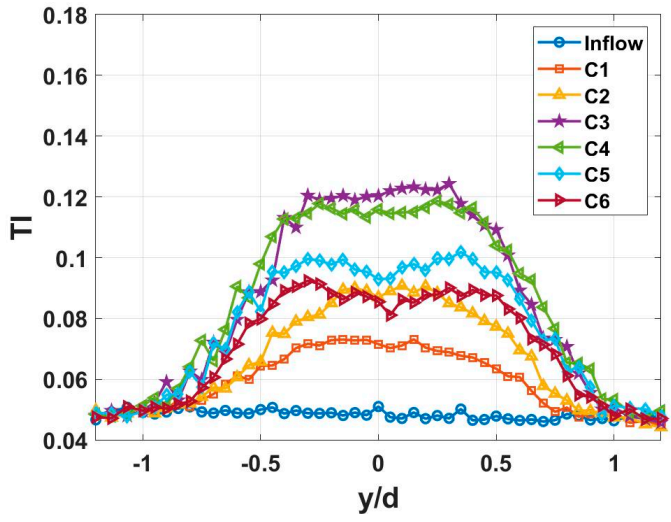

(c)

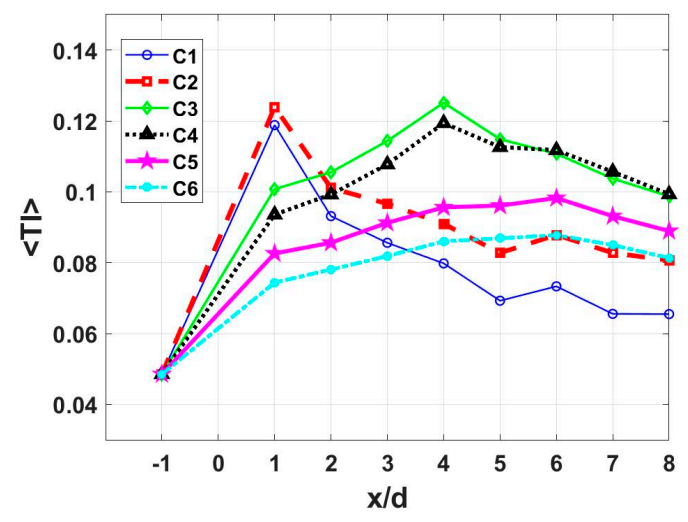

(d)

Figure 12. Lateral profiles of the TI under the C1-C6 TSRs at the streamwise locations: $x / d=1(a)$; $\mathrm{x} / \mathrm{d}=3(\mathrm{~b})$; and $\mathrm{x} / \mathrm{d}=5(\mathrm{c})$; and the streamwise distribution of the laterally-averaged TI (d). Here, the angle bracket represents a laterally spatial averaging from $y / d=-0.5$ to 0.5 .

The generation of active wake-enhanced TI is observed in the rotor positions near the blade root (or the nacelle) and the blade tip. The maximum TI under each TSR condition occurs in the downstream locations where the wake turbulence induced from the nacelle and the blade tip merge at $x / d=1$ to 2 in the $\mathrm{C} 1$ and $\mathrm{C} 2$ cases, $\mathrm{x} / \mathrm{d}=4$ in the $\mathrm{C} 3$ and $\mathrm{C} 4$ cases, and $\mathrm{x} / \mathrm{d}=5$ to 6 in the $\mathrm{C} 5$ and $\mathrm{C} 6$ cases. Hence, the position with the occurrence of the TI enhancement extends to a further downstream location with the TSR increment. Regarding the variability of the TI magnitude, the turbine at the C3 and C4 conditions produces an overall TI much higher than that at the other conditions. Within the turbine rotor, the enhanced TI near the blade tip becomes stronger with TSR increment in the C1-C4 conditions, whereas the TI near the root gradually weakens with TSR increment in the C2-C6 conditions. This result, together with the wake velocity, is shown in Figures 7 and 8 where the presence of large wake velocity deficits leads to strong mean velocity gradients, which promote the generation of the active wake-enhanced TI. This behavior indicates that a certain segment of the blade effective for torque generation extends from the root position toward the blade tip position with the increase of the TSR.

In the six TSR conditions, the power outputs increase and then decrease with the increment of the blade rotating speeds (or TSRs), under which the magnitudes in the wake velocity deficits and the enhanced turbulence intensity show a similar trend of increasing first and then decreasing. The maximum power coefficient is found to appear on the turbine operating at the C4 condition (TSR $=4.1$ ). Furthermore, the comparison of the TI magnitude at the C 3 and C5 conditions reveals a remarkable difference, where the turbine at the $\mathrm{C} 5$ condition produces a larger power output and a turbine wake with a smaller TI magnitude compared with the turbine operating at the C3 condition. This result accounts for a larger power output of a wind turbine that can be achieved through the regulation with a higher blade angular velocity and a smaller shaft torque. Under this condition, the turbine-generated wake has lower velocity deficits and less TI enhancement, which is beneficial to the power production efficiency on the downstream turbines in a large wind farm.

Note that at the $\mathrm{C} 2$ condition both the mean streamwise velocity and the TI show a V shape distribution at $x / d=1$, with the larger velocity deficit (also associated with larger wind shear) and stronger enhanced TI in the inner circle region. By coincidence, this behavior accounts for the rotor within the inner circle region at this operating condition extracting more momentum from the incoming flow and leads to the V-like wake velocity distribution and turbulence intensity distribution. The presence of larger wind shear in the wake facilitates strong turbulent mixing, which results in a U-like wake velocity distribution at the downstream locations of $\mathrm{x} / \mathrm{d}=3$ and 5 . 
Figure 13 presents the contours of the lateral momentum flux in the hub-level horizontal plane for the turbine operating at the different TSR conditions. Here, the lateral momentum flux is computed from the covariance of the two instantaneous streamwise and spanwise velocity components as

$$
\overline{u^{\prime} v^{\prime}}=\overline{(u-\bar{u})(v-\bar{v})},
$$

where the overbar denotes temporal average, $\overline{u^{\prime} v^{\prime}}$ is the lateral momentum flux, and $u$ and $v$ are instantaneous streamwise and spanwise velocity components, respectively. The magnitude of the momentum flux can be applied to explain the direction and extent of momentum transport in the turbine-induced wake area. As shown in Figure 13, the positive and negative momentum fluxes represent the upward and downward fluxes (on the figure), respectively, to facilitate the momentum transfer inward to the turbine wakes. As shown in Figure 7, the large wake velocity deficits appear on the turbine rotor operating at the $\mathrm{C} 3$ and $\mathrm{C} 4$ conditions, which are, of course, expected to require more momentum transported from adjacent flows to promote wake recovery. Hence, it can also be expected that increases in the magnitude of the lateral momentum flux in the wake region are relatively larger in the $\mathrm{C} 3$ and $\mathrm{C} 4$ conditions than the others. This behavior indicates that larger wake velocity deficits correspond to the stronger momentum fluxes.

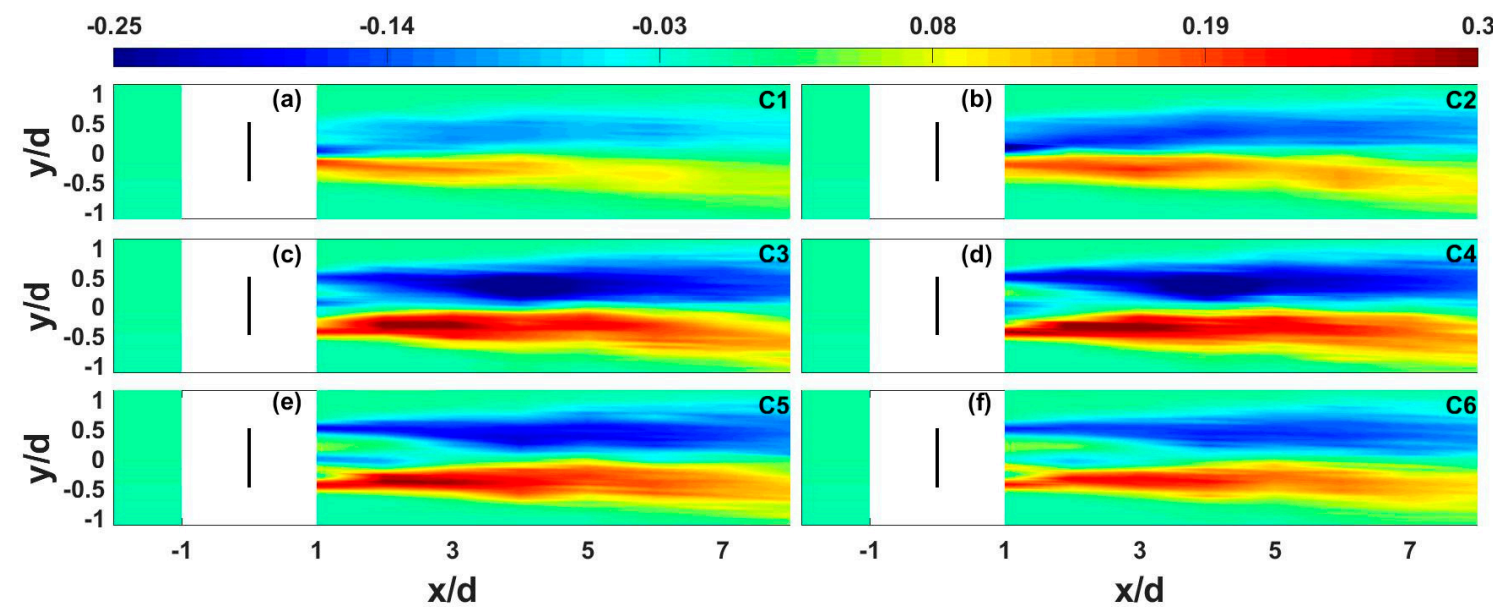

Figure 13. Contour plots of the lateral momentum flux under different TSRs of: (a) 0.9 ; (b) 1.5 ; (c) 3.0; (d) 4.1 ; (e) 5.2; and (f) 5.9, corresponding to C1-C6 conditions, respectively.

\section{Summary}

A wind tunnel experiment was carried out to investigate the power generation efficiency and turbulent characteristics in the wake from the stand-alone miniature wind turbine operating at different tip speed ratios (TSRs) with the same incoming flow speed. We used the Maxon DCX-12-L motor as the turbine generator, which was connected to a resistor and a dc voltmeter in a series circuit. The resistor could be adjusted to achieve the turbine blade rotating at the different angular velocities (i.e., different TSRs) under the same hub-level incoming velocity of $6.1 \mathrm{~m} \mathrm{~s}^{-1}$. The TSRs considered are: 0.9 , 1.5, 3.0, 4.1, 5.2, and 5.9. A dc voltmeter was used to measure the total resistance and the current in the circuit at each TSR condition. A Cobra probe was used to measure the three velocity components (streamwise, spanwise, and vertical) at positions across the turbine wakes and the inflow velocity. Vital turbulence statistics calculated from the measured instantaneous wind velocity components include the mean streamwise velocity, the mean vertical velocity, the total turbulence intensity, and the lateral momentum flux.

In the six TSR conditions, the power outputs increase and then decrease with the increment of the blade rotating speeds (or TSRs), under which the magnitudes in the wake velocity deficits and the enhanced turbulence intensity show a similar trend of increasing first and then decreasing. The 
maximum power coefficient is found to appear on the turbine operating at the C4 condition (TSR $=4.1$ ). In this condition, the turbine produces the maximum power output and torque, as well as the strongest wake with the largest velocity deficits, turbulence intensity levels, and momentum fluxes. In general, the $\mathrm{C} 4$ condition is the best power generation efficiency state for wind turbine design, and it can produce the strongest wake affecting the downstream wind turbine power generation efficiency of large wind power plants. Compared to optimizing farm power generation efficiency by blade pitch regulation reported in [21], the control of the load in the electrical loop can be considered another moderate way to influence the strength of the turbine wake and the overall farm power production. The experimental investigation on the turbine operations at the $\mathrm{C} 5$ and $\mathrm{C} 3$ conditions shows that the turbine at $\mathrm{C} 5$ produces more power output and less torque as well as a weaker wake, whereas the turbine at $\mathrm{C} 3$ generates less power output and more torque that leads to a stronger wake with larger velocity deficits and more intense turbulence intensity. This result comparison between C 3 and C5 demonstrates that a turbine operating at a faster blade rotating speed can generate a larger power output and extract less momentum from the inflow to produce a slightly weaker wake. This kind of control strategy can be applied to raise the power generation of the downstream turbines as well as the overall power productivity in large wind farms with different inflow conditions and placement configurations [26,27].

Author Contributions: Conceptualization, Y.-T.W.; methodology, C.-Y.L. and Y.-T.W.; software, C.-Y.L.; validation, C.-Y.L., C.-M.H. and Y.-T.W.; formal analysis, C.-Y.L., C.-M.H. and Y.-T.W.; investigation, C.-Y.L., C.-M.H. and Y.-T.W.; resources, Y.-T.W.; data curation, Y.-T.W.; writing-original draft preparation, C.-Y.L., C.-M.H. and Y.-T.W.; writing-review and editing, Y.-T.W.; visualization, C.-Y.L., C.-M.H. and Y.-T.W.; supervision, Y.-T.W.; project administration, Y.-T.W.; funding acquisition, Y.-T.W. All authors have read and agreed to the published version of the manuscript.

Funding: The authors have received research grants from MOST, grant numbers: 107-2221-E-006-228, 108-2221-E-006-077, and 108-3116-F-006-013. The authors have also received research funding from the Project of Taiwan's Deep Decarbonization Pathways toward a Sustainable Society (Grant No. AS-KPQ-106-DDPP) from the Academia Sinica, Taiwan. This research was also supported in part by Higher Education Sprout Project, Ministry of Education to the Headquarters of University Advancement at National Cheng Kung University.

Acknowledgments: Computing resources were provided by the Taiwan National Center for High-performance Computing (NCHC).

Conflicts of Interest: The authors declare that they have no conflict of interest.

\section{Nomenclature}

\begin{tabular}{lll}
\hline Variable & Physical Meaning & Unit \\
\hline$\alpha$ & Blade angular acceleration & $\mathrm{rad} \cdot \mathrm{s}^{-2}$ \\
$\lambda$ & Tip speed ratio & - \\
$v$ & Kinematic viscosity & $\mathrm{m} \cdot \mathrm{s}^{-1}$ \\
$\varrho$ & Air density & $\mathrm{kg} \cdot \mathrm{m}^{-3}$ \\
$\sigma_{u}$ & Streamwise velocity variance & $\mathrm{m} \cdot \mathrm{s}^{-1}$ \\
$\sigma_{v}$ & Spanwise velocity variance & $\mathrm{m} \cdot \mathrm{s}^{-1}$ \\
$\sigma_{w}$ & Vertical velocity variance & $\mathrm{m} \cdot \mathrm{s}^{-1}$ \\
$\Omega$ & Blade angular velocity & $\mathrm{rpm}$ \\
$A$ & Rotor-swept area & $\mathrm{m}$ \\
$C_{1} \sim C_{6}$ & Experimental cases & - \\
$C_{p}$ & Power coefficient & - \\
$C_{p, m e c h}$ & Mechanical power coefficient & - \\
DCPS & Direct current power supply & - \\
\hline
\end{tabular}




\begin{tabular}{|c|c|c|}
\hline Variable & Physical Meaning & Unit \\
\hline$I$ & Electrical current & A \\
\hline$I_{M}$ & Inertia of the mechanical moment & $\mathrm{kg} \cdot \mathrm{m}^{2}$ \\
\hline$I_{u}$ & Streamwise turbulence intensity & - \\
\hline$I_{v}$ & Spanwise turbulence intensity & - \\
\hline$I_{w}$ & Vertical turbulence intensity & - \\
\hline$L_{\text {blade }}$ & Friction-induced torque of the blade surface & $\mathrm{mN} \cdot \mathrm{m}$ \\
\hline$L_{g e n}$ & Friction-induced torque of the generator shaft & $\mathrm{mN} \cdot \mathrm{m}$ \\
\hline$P_{f}$ & Friction-induced power loss & $\mathrm{mW}$ \\
\hline$P_{m}$ & Mechanical power & $\mathrm{mW}$ \\
\hline$P_{0}$ & Power output & $\mathrm{mW}$ \\
\hline Qblade & Torque loss of the blade surface & $\mathrm{mN} \cdot \mathrm{m}$ \\
\hline$Q_{m}$ & Mechanical torque & $\mathrm{mN} \cdot \mathrm{m}$ \\
\hline$Q_{o}$ & Electromagnetic torque & $\mathrm{mN} \cdot \mathrm{m}$ \\
\hline$Q_{\text {shaft }}$ & Torque loss of the generator shaft & $\mathrm{mN} \cdot \mathrm{m}$ \\
\hline$R_{t}$ & Total resistance & Ohm \\
\hline$R e_{\text {chord }}$ & Chord-based Reynolds number & - \\
\hline$R e_{d}$ & Diameter-based Reynolds number & - \\
\hline$t$ & Time & $\mathrm{s}$ \\
\hline$T_{\text {blade }}$ & Friction-induced torque loss from the blade surface & $\mathrm{mN} \cdot \mathrm{m}$ \\
\hline$T_{g e n}$ & Friction-induced torque loss from the generator shaft & $\mathrm{mN} \cdot \mathrm{m}$ \\
\hline$T_{m}$ & Mechanical torque constant & $\mathrm{mN} \cdot \mathrm{m}$ \\
\hline$T_{o}$ & Electromagnetic torque constant & $\mathrm{mN} \cdot \mathrm{m}$ \\
\hline$T I$ & Turbulence intensity & - \\
\hline$V$ & Voltage & $\mathrm{V}$ \\
\hline $\bar{c}$ & Average chord & $\mathrm{m}$ \\
\hline$d$ & Rotor diameter & $\mathrm{m}$ \\
\hline$f_{\text {gen }}$ & Fricitonal coefficient & - \\
\hline$m_{\text {disk }}$ & Weight of the circular aluminum disk & $\mathrm{kg}$ \\
\hline$m_{\text {rotor }}$ & Weight of the rotor & $\mathrm{kg}$ \\
\hline$r$ & Radius of the circular aluminum disk & $\mathrm{m}$ \\
\hline $\bar{u}_{h u b}$ & Incoming mean velocity at the hub height & $\mathrm{m} \cdot \mathrm{s}^{-1}$ \\
\hline $\bar{u}_{t i p}$ & Blade tip speed & $\mathrm{m} \cdot \mathrm{s}^{-1}$ \\
\hline$x$ & Streamwise location & $\mathrm{m}$ \\
\hline$y$ & Spanwise location & $\mathrm{m}$ \\
\hline$z$ & Vertical location & $\mathrm{m}$ \\
\hline
\end{tabular}

\section{References}

1. Iungo, G.; Wu, Y.; Porte-Agel, F. Field Measurements of Wind Turbine Wakes with Lidars. J. Atmos. Ocean. Technol. 2013, 30, 274-287. [CrossRef]

2. Iungo, G.; Porte-Agel, F. Volumetric Lidar Scanning of Wind Turbine Wakes under Convective and Neutral Atmospheric Stability Regimes. J. Atmos. Ocean. Technol. 2014, 31, 2035-2048. [CrossRef]

3. Hu, W.Y.; Jiaqiang, E.; Deng, Y.W.; Li, L.J.; Han, D.D.; Zhao, X.H.; Zhang, Z.Q.; Peng, Q.G. Effect analysis on power coefficient enhancement of a convective wind energy collecting device in the expressway. Energy Convers. Manag. 2018, 171, 249-271. [CrossRef]

4. Dou, B.Z.; Guala, M.; Lei, L.; Zeng, P. Experimental investigation of the performance and wake effect of a small-scale wind turbine in a wind tunnel. Energy 2019, 166, 819-833. [CrossRef]

5. Wu, Y.; Porte-Agel, F. Large-Eddy Simulation of Wind-Turbine Wakes: Evaluation of Turbine Parametrisations. Bound. Layer Meteorol. 2011, 138, 345-366. [CrossRef]

6. Wu, Y.; Porte-Agel, F. Atmospheric Turbulence Effects on Wind-Turbine Wakes: An LES study. Energies 2012, 5, 5340-5362. [CrossRef]

7. Troldborg, N.; Sorensen, J.N.; Mikkelsen, R. Numerical simulations of wake characteristics of a wind turbine in uniform inflow. Wind Energy 2010, 13, 86-99. [CrossRef] 
8. Chamorro, L.; Arndt, R.; Sotiropoulos, F. Reynolds number dependence of turbulence statistics in the wake of wind turbines. Wind Energy 2012, 15, 733-742. [CrossRef]

9. Chamorro, L.; Porte-Agel, F. A Wind-Tunnel Investigation of Wind-Turbine Wakes: Boundary-Layer Turbulence Effects. Bound. Layer Meteorol. 2009, 132, 129-149. [CrossRef]

10. Chamorro, L.; Porte-Agel, F. Effects of Thermal Stability and Incoming Boundary-Layer Flow Characteristics on Wind-Turbine Wakes: A Wind-Tunnel Study. Bound. Layer Meteorol. 2010, 136, 515-533. [CrossRef]

11. Zhang, W.; Markfort, C.; Porte-Agel, F. Wind-Turbine Wakes in a Convective Boundary Layer: A Wind-Tunnel Study. Bound. Layer Meteorol. 2013, 146, 161-179. [CrossRef]

12. Iungo, G.V. Experimental characterization of wind turbine wakes: Wind tunnel tests and wind LiDAR measurements. J. Wind Eng. Ind. Aerodyn. 2016, 149, 35-39. [CrossRef]

13. Mallipudi, S.; Selig, M.; Long, K. Use of a Four Hole Cobra Pressure Probe to Determine the Unsteady Wake Characteristics of Rotating Objects. In Proceedings of the 24th AIAA Aerodynamic Measurement Technology and Ground Testing Conference, Portland, OR, USA, 28 June 2004-1 July 2004; p. 2299.

14. Chawla, J.S.; Suryanarayanan, S.; Puranik, B.; Sheridan, J.; Falzon, B.G. Efficiency improvement study for small wind turbines through flow control. Sustain. Energy Technol. Assess. 2014, 7, 195-208. [CrossRef]

15. Wang, Z.Y.; Tian, W.; Ozbay, A.; Sharma, A.; Hu, H. An experimental study on the aeromechanics and wake characteristics of a novel twin-rotor wind turbine in a turbulent boundary layer flow. Exp. Fluids 2016, 57, 150. [CrossRef]

16. Wu, Y.-T.; Lin, C.-Y.; Huang, C.-E.; Lyu, S.-D. Investigation of multiblade wind-turbine wakes in turbulent boundary layer. J. Energy Eng. 2019, 145, 04019023. [CrossRef]

17. Bottasso, C.L.; Campagnolo, F.; Petrovic, V. Wind tunnel testing of scaled wind turbine models: Beyond aerodynamics. J. Wind Eng. Ind. Aerodyn. 2014, 127, 11-28. [CrossRef]

18. Lee, M.H.; Shiah, Y.C.; Bai, C.J. Experiments and numerical simulations of the rotor-blade performance for a small-scale horizontal axis wind turbine. J. Wind Eng. Ind. Aerodyn. 2016, 149, 17-29. [CrossRef]

19. MacPhee, D.W.; Beyene, A. Performance analysis of a small wind turbine equipped with flexible blades. Renew. Energy 2019, 132, 497-508. [CrossRef]

20. Chen, Y.J.; Shiah, Y.C. Experiments on the Performance of Small Horizontal Axis Wind Turbine with Passive Pitch Control by Disk Pulley. Energies 2016, 9, 353. [CrossRef]

21. Dilip, D.; Porte-Agel, F. Wind Turbine Wake Mitigation through Blade Pitch Offset. Energies 2017, $10,757$. [CrossRef]

22. Manwell, J.F.; McGowan, J.G.; Rogers, A.L. Wind Energy Explained: Theory, Design and Application; Wiley: Hoboken, NJ, USA, 2010.

23. Bastankhah, M.; Porte-Agel, F. A New Miniature Wind Turbine for Wind Tunnel Experiments. Part I: Design and Performance. Energies 2017, 10, 908. [CrossRef]

24. Hyvärinen, A.; Segalini, A. Effects from complex terrain on wind-turbine performance. J. Energy Resour. Technol. 2017, 139. [CrossRef]

25. Stull, R.B. An Introduction to Boundary Layer Meteorology; Springer: Berlin/Heidelberg, Germany, 1988.

26. Wu, Y.-T.; Liao, T.-L.; Chen, C.-K.; Lin, C.-Y.; Chen, P.-W. Power output efficiency in large wind farms with different hub heights and configurations. Renew. Energy 2019, 132, 941-949. [CrossRef]

27. Wu, Y.-T.; Lin, C.-Y.; Chang, T.-J. Effects of inflow turbulence intensity and turbine arrangements on the power generation efficiency of large wind farms. Wind Energy 2020, 1-16. [CrossRef]

(C) 2020 by the authors. Licensee MDPI, Basel, Switzerland. This article is an open access article distributed under the terms and conditions of the Creative Commons Attribution (CC BY) license (http://creativecommons.org/licenses/by/4.0/). 